\title{
Simplified Liver Splitting Technique Using a Curved Chang's Needle
}

\section{Yu-Chung Chang ${ }^{1,5 *}$, Naofumi Nagasue ${ }^{2}$, Chu-San Chen ${ }^{3}$ and Aiken Wang ${ }^{4}$}

${ }^{1}$ Department of Surgery, National Cheng Kung University Hospital, College of Medicine, National Cheng Kung University, Taiwan

${ }^{2}$ Department of Surgery, Fukumitsu Hospital, Japan

${ }^{3}$ Department of Mechanical Engineering and Graduate Studies, National Cheng Kung University, Taiwan

${ }^{4}$ Mold Wang Precision Co., Ltd. Yung-Kang District, Taiwan

${ }^{5}$ Department of Surgery, Masuda Medical Association Hospital, Japan

\begin{abstract}
Liver-splitting techniques been previously developed for ex vivo and in situ cadaveric liver transplantation, and more recently for in situ living donor liver transplantation or liver partition with a portal vein ligation for a staged hepatectomy. We report a novel and simplified technique using a long curved needle to make whole-thickness mattress sutures along the division line of the remnant liver above the inferior vena cava to control bleeding, and then bloodlessly splitting the liver with scissors within $40 \mathrm{~min}$ in a case of a left lobectomy with metastases from breast cancer. The patient was uneventfully discharged on the fourth postoperative day.
\end{abstract}

When a liver lobectomy or partition to enhance liver regeneration for a staged hepatectomy is necessary, this technique can be done straightforwardly without concern for the problems of venous return or congestion of the recipient or remnant donor liver. This technique is probably the simplest and fastest way for any surgeon and any facility.

Keywords: Hepatic lobectomy; Liver transplantation; Liver splitting; Staged hepatectomy; Liver partition; Chang's needle; ALPPS

\section{Introduction}

The author has been developing a technique for simplifying hepatic resections [1-4] and intrahepatic inflow/outflow control [3,4] by using whole-thickness mattress sutures applied with a long straight needle; however, the liver over the inferior vena cava is a limitation for such a whole-thickness liver-puncture maneuver. To overcome this obstacle, a modification has recently been made to a long curved needle to enable liver puncturing from the bottom of the liver to the top. Here we report a case of left hepatic lobectomy using this novel technique for liver splitting.

\section{Materials and Methods}

A 51 year old woman was referred to our department for left-lobe liver metastases secondary to breast cancer. Three years previously, she had undergone a left-side mastectomy and, one year later, was multiple recurrences of liver tumors. Since then, she underwent chemotherapy and target therapy, and the tumors almost completely disappeared. Last year, however, the liver tumors recurred in left lobe. She came to seek a possibility of surgical resection. After careful evaluations for the surgical indication, she was given an open left hepatic lobectomy in August, 2012. After the laparotomy, intraoperative ultrasonography and visual inspection showed four tumors in the left lobe. The operation was started with a suture ligation of the extrahepatic left Glissonian pedicle using a No. 1 silk with a conventional curved needle (Figure 1 \#1). Two overlapping interlocking whole-thickness mattress sutures (3-5 cm wide) were then made from the lower liver border upward with our self-designed long curved needle (Figure 2), bent from a long straight Chang's needle $(19 \mathrm{~cm})$, by puncturing from liver bottom toward the liver surface along the division line of the remnant side liver above the inferior vena cava (Figure $1 \# 2-\# 9$ ). This procedure enabled the surgeon to cut a one-knot-length (3-5 cm wide) liver parenchymal division using scissors (Figure 1 \#10). Surprisingly, the liver did not bleed. The third knot was applied upward and the second knot-length liver parenchymal division followed with the same bloodless result (Figure 1 \#11). Finally, the fourth knot reached the upper border of the liver, and the rest of the liver division was completed (Figure 1 \#12) with scissors as well. After liver splitting had been completed, the left
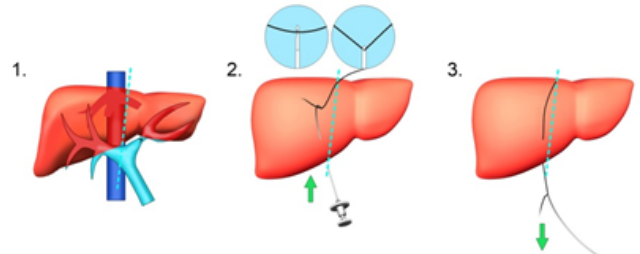
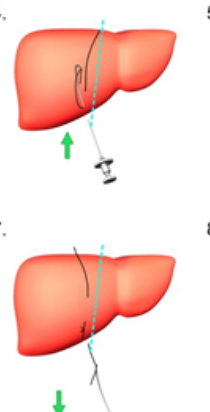

10.

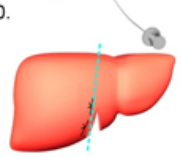

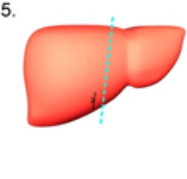
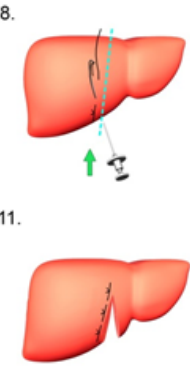

6.
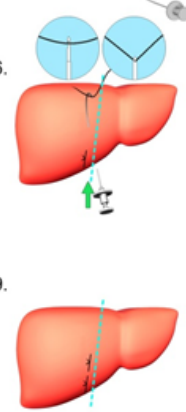

12.

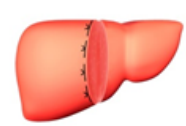

Figure 1: Schematic representations of the current technique used for a left hepatic lobectomy in the current case.

*Corresponding author: Dr. Yu-Chung Chang, Department of Surgery, Masuda Medical Association Hospital, 1917-2, Toda-cho, Masuda, Shimane 699-3676, Japan, Tel: +81-856-223611; Fax: +81-856-220407; E-mail: changmdphd@yahoo.com

Received January 20, 2017; Accepted January 30, 2017; Published February 05, 2017

Citation: Chang YC, Nagasue N, Chen CS, Wang A (2017) Simplified Liver Splitting Technique Using a Curved Chang's Needle. Hepatol Pancreat Sci 1: 103

Copyright: (c) 2017 Chang YC, et al. This is an open-access article distributed under the terms of the Creative Commons Attribution License, which permits unrestricted use, distribution, and reproduction in any medium, provided the original author and source are credited. 


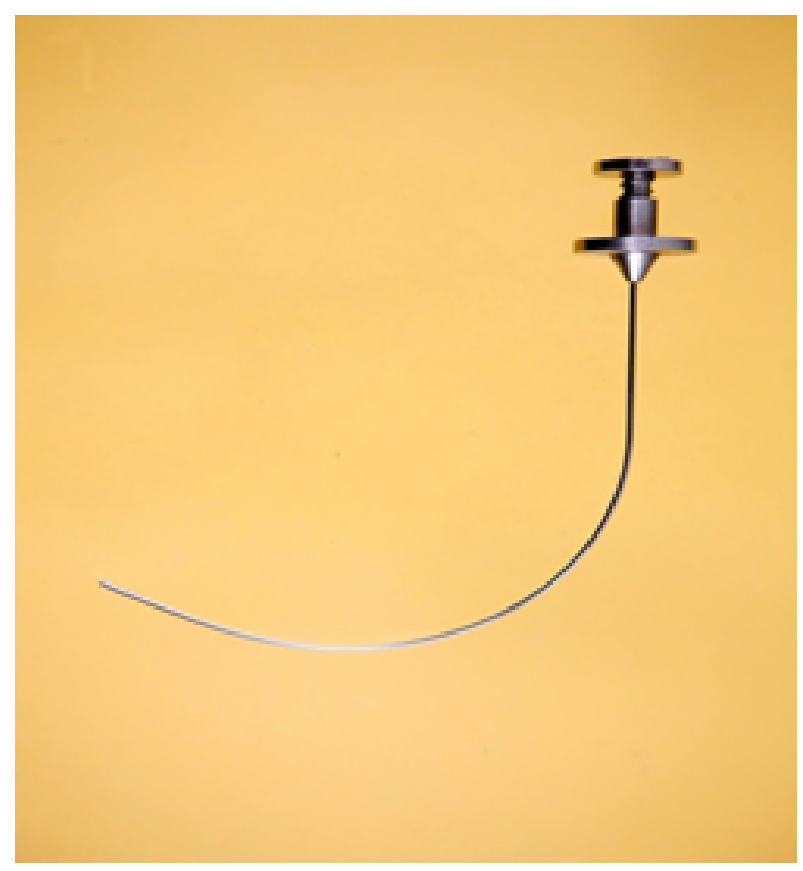

Figure 2: A curved Chang's needle.

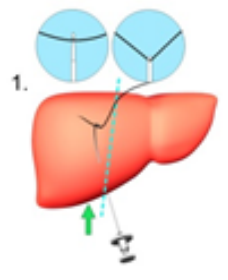

2.
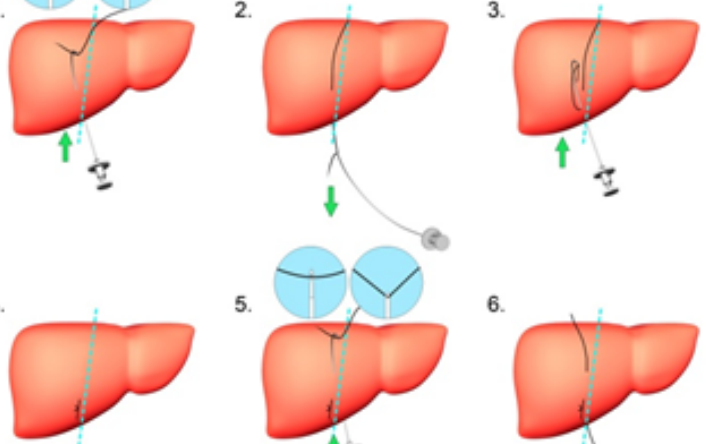

7.

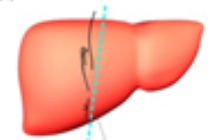

$\uparrow \mathrm{E}$

10.

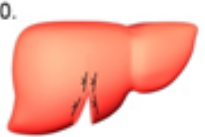

5.
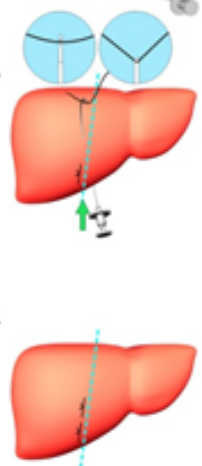

11.

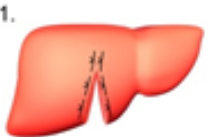

hilar Glissonian structures and the left hepatic vein were dissected and ligated, respectively. Neither fibrin sealant nor a coagulation product was used. A Jackson-Pratt drain was placed along the resected area before the abdomen was closed.

\section{Results}

The parenchymal transsection-4 whole-thickness interlocking mattress sutures and liver splitting (parenchymal division) using scissors-required only $40 \mathrm{~min}$ and there was no bleeding. Procedurerelated complications, such as postoperative bleeding, bile leakage, liver infarction, liver abscess, subphrenic abscess and ensuing sepsis, were not encountered. The patient recovered uneventfully and was discharged on the 4 th day post-operation.

\section{Discussion}

Liver splitting has been used since 1987 as an ex vivo [5-7] (one liver for two grafts) technique and since 1988 as in situ [8-11] (left lateral segment form living donor liver) technique increase liver grafts for pediatric liver transplantation. Since then, splitting techniques have been used for in situ [12,13] cadaveric liver transplantation, living donor transplantation using the right lobe for children [14] and adults [15] and recently for patients with insufficient liver capacity patients who need liver partition, and concomitantly with portal vein ligation to increase liver regeneration for staged hepatectomy [16] (ALPPS).

Currently, ultrasonic dissectors and coagulators are used for liver splitting without vascular control for right-lobe grafts in living-donor liver transplantation; however, significant blood is lost and more than 6 $\mathrm{h}$ of surgery (first 11 donors, range 10.1-15.5 h) [17] is usually necessary. Pringle's maneuver and selective vascular control [18] during the parenchymal transection may be used to control recalcitrant bleeding.

Other than currently used parenchyma transection devices the author has been developing a technique for simplifying hepatic resections $[1,2,4]$ and intrahepatic inflow/outflow control $[3,4]$ by using whole-thickness mattress sutures applied with a long straight needle since 1996; however, the liver over the inferior vena cava is a limitation for such a whole-thickness liver-puncture maneuver. To overcome this obstacle, a modification has recently been made to a long curved needle to enable liver puncturing from the bottom of the liver to the top. The history of suture-compression technique for liver resection can be traced back to 1896 when liver operation was begun and since them straight and curve needles had been applied [19]; however current report is the first application of long curved needle on liver splitting and left hepatic lobectomy. The speedy and bloodless results have beyond the author's imagination.

The author's curved needle maneuver can simplify the cumbersome and time-consuming parenchymal transection procedures using scissors in cases of a left lateral segment graft for pediatric liver transplantation or in parts of the right- or left-lobe graft procurement procedures, for which meticulous dissection along the middle hepatic vein is not needed. Liver-splitting or partition time and blood loss can be reduced. Because no hilar or vascular control is required, ischemic injury can be obviated for the graft or donor remnant liver. Hilar structures can be approached after parenchymal splitting, in which case any unnecessary injury to the blood supply of the bile duct $[13,17]$ can be minimized.

\section{Conclusion}

When a liver lobectomy or partition to enhance liver regeneration for a staged hepatectomy is necessary, this technique can be done straightforwardly without concern for the problems of venous return

Figure 3: Schematic representations of the current technique used for liver splitting. 
Citation: Chang YC, Nagasue N, Chen CS, Wang A (2017) Simplified Liver Splitting Technique Using a Curved Chang's Needle. Hepatol Pancreat Sci 1: 103.

or congestion of the recipient or remnant donor liver. This technique is probably the simplest and fastest way for any surgeon and any facility.

\section{Conflict of Interest}

Authors have no conflict of interests to declare.

\section{References}

1. Chang YC, Nagasue N, Lin XZ, Chen CS (2001) Easier hepatic resections with a straight needle. Am J Surg 182: 260-264

2. Chang YC, Nagasue N, Chen CS, Lin XZ (2006) Simplified hepatic resections with the use of a Chang's needle. Ann Surg 243: 169-172.

3. Chang YC, Nagasue N (2008) Blocking intrahepatic inflow and backflow using Chang's needle during hepatic resection: Chang's maneuver. HPB 10: 244-248.

4. Chang YC (2012) Open hepatic resection using Chang's needle In: Di Carlo I, eds. Open, Laparoscopic and Robotic Hepatic Resection. Milan: SpringerVerlag Italia, pp: 13-22.

5. Pichlmayr R, Ringe B, Gubernatis G, Hauss J, Bunzendahl H (1988) Transplantation einer Spenderleber auf zwei Empfänger (SplittingTransplantation) - Eine neue Methode in der Weiterentwicklung der Lebersegmenttransplantation. Langebecks Arch Chir 373: 127-130.

6. Bismuth H, Morino M, Castaing D (1989) Emergency orthotopic liver transplantation in two patients using one donor liver. Br J Surg 76: 722-724.

7. Emond JC, Whitington PF, Thistlethwaite JR (1990) Transplantation of two patients with one liver: analysis of a preliminary experience with split-liver grafting. Ann Surg 212: 14-22.

8. Raia S, Nery JR, Mies S (1989) Liver transplantation from live donors. Lance 2: 497.
9. Strong RW, Lynch SV, Ong TN (1990) Successful liver transplantation from a living donor to her son. N Engl J Med 322: 1505-1507.

10. Nagasue N, Kohno H, Matsuo S (1992) Segmental (partial) liver transplantation from a living donor. Transplant Proc 24: 1958-1959.

11. Broelsch CE, Whitington PF, Emond JC (1991) Liver transplantation in children from living related donors: Surgical techniques and results. Ann Surg 214: 429439

12. Rogier X, Malago M, Habib N (1995) In situ splitting of the liver in the heartbeating cadaveric organ donor for the transplantation in two recipients. Transplantation 59: 1081-1083.

13. Busuttil RW, Goss JA (1999) Split liver transplantation. Ann Surg 229: 313-321.

14. Yanaoka Y, Washida M, Honda K (1994) Liver transplantation using a right graft from a living related donor. Transplantation 57: 1127-1130.

15. Lo CM, Fan ST, Liu CL (1997) Extending the limitation on the size of adult recipient in living donor liver transplantation using extended right lobe graft. Transplantation 63: 1524-1528.

16. Schnitzbauer AA, Lang SA, Goessmann H (2012) Right portal vein ligation combined with in situ splitting induces rapid left lateral liver lobe hypertrophy enabling 2-staged extended right hepatic resection in small-for-size settings. Ann Surg 255: 405-414.

17. Fan ST, Lo CM, Liu CL (2000) Technical refinement in adult-to-adult living donor liver transplantation using right lobe graft. Ann Surg 231: 126-131.

18. Imamura H, Kokudo N, Sugawara Y (2004) Pringle's maneuver and selective inflow occlusion in living donor liver hepatectomy. Liver Transpl 10: 771-778.

19. Komorowski AL, Lukashenko A, Chang YC (2013) The past and present of liver suture. World J Surg 38: 512-518. 